\title{
O PROCESSO DE PROJETO E A NBR 15.575:2013: O PAPEL DA COORDENAÇÃO DE PROJETOS
}

BARBOSA, Patrícia Elizabeth Ferreira Gomes

Instituto Metodista Izabela Hendrix, email: patrícia.barbosa@izabelahendrix.com.br ANDERY, Paulo Roberto Pereira

Escola de Engenharia da UFMG, e-mail: pandery@ufmg.br

\begin{abstract}
RESUMO
O presente trabalho apresenta estudo diagnóstico sobre o processo de projeto em empresas incorporadoras e construtoras, focando o atendimento à NBR 15.575:2013. O método de pesquisa envolveu estudo de caso múltiplo, realizado em seis empresas incorporadoras, sendo empregadas como fontes de evidência entrevistas, análise de projeto e documentos do sistema de gestão da qualidade das empresas. Ênfase foi dada ao estudo de novas ações da coordenação de projetos, em suas várias vertentes. Os resultados indicam que a implementação de processos para atendimento à NBR 15.575:2013 tem sido indutor de mudanças e inovações na relação entre as equipes de projeto e as demais funções da produção dos empreendimentos, ao implementar sistemicamente as ferramentas previstas na NBR 15.575:2013 e incorporadas nos sistemas de gestão das empresas.
\end{abstract}

Palavras-chave: Norma de Desempenho; Processo de Projeto para desempenho; Coordenação de projetos; Inovação.

\begin{abstract}
The present work aims presenting a diagnostic study of a research project focusing the design process in Real Estate companies, with emphasis on NBR 15.575:2013 assurance. The research method involved multiple case studies, carried out on six building construction companies, with the analysis of design drawings and documents, interviews and quality assurance system documents. The innovations on design coordination are discussed. The results point out that the implementation of processes of NBR 15.575: 2013 assurance has been an inducer of changes and innovations in the relationship between design teams and other functions of the Project, by systematically implementing the tools provided in NBR 15.575: 2013 and incorporated into management systems
\end{abstract}

Keywords: Performance Standard; Performance based Design Process; Design Coordination; Innovation

\section{INTRODUÇÃO}

Ações para garantia do desempenho em empreendimentos habitacionais, tendo como referência a NBR 15.575: Edificações Habitacionais - Desempenho (ABNT, 2013), vêm crescendo em amplitude e importância nas práticas de mercado, por vários motivos. Em primeiro lugar, em função da demanda dos clientes, que incorporaram o conceito de desempenho às noções de qualidade dos produtos do mercado imobiliário. Por outro lado, as empresas incorporadoras e construtoras dão-se conta da necessidade de reduzir riscos do não atendimento dos requisitos normativos, por razões legais ou de mercado. A isso somam-se as exigências do Sistema de Avaliação da

BARBOSA, P. E. F. G.; ANDERY, P. R. P. O processo de projeto e a NBR 15.575-2013: o papel da coordenação de projetos. In: SIMPÓSIO BRASILEIRO DE QUALIDADE DO PROJETO NO AMBIENTE CONSTRUÍDO, 6., 2019, Uberlândia. Anais... Uberlândia: PPGAU/FAUeD/UFU, 2019. p. 148-154. DOI https://doi.org/10.14393/sbqp19015. 
Conformidade (SIAC) no âmbito do Programa Brasileiro de Qualidade e Produtividade do Habitat (PBQP-H), bem como a exigências por parte de agentes financeiros, que condicionam a concessão de financiamentos ao atendimento aos requisitos da Norma de Desempenho, como ficou popularmente conhecida a NBR 15.575:2013.

O processo de projeto passa a ser estratégico para o atendimento ao desempenho no que tange as soluções adotadas e em inovações no seu desenvolvimento. Diversos trabalhos recentes apontam para a necessidade de uma visão mais sistêmica desse processo, a necessidade de definições mais assertivas nos escopos de contratação de disciplinas de projeto, a padronização de soluções construtivas e a introdução de processos nos sistemas de gestão da qualidade para garantia do desempenho (OTTERO E SPOSTO, 2016; COTTA e ANDERY, 2018; SANTOS e SANTOS, 2018, ANDERY e BARBOSA, 2018).

Okamoto (2015) já constatava de que o atendimento às exigências da Norma de Desempenho implicaria na necessidade de implementação de uma visão mais integrada e sistêmica do processo de projeto em sua relação com as demais fases do empreendimento. Conclusões similares foram apresentadas por Barbosa e Andery (2016) ressaltaram a necessidade de maior integração entre a função desenvolvimento do produto no mercado imobiliário - da qual a etapa de projetos é uma fase - e outras funções, em especial a etapa de incorporação imobiliária e a execução das obras.

Na mesma linha de raciocínio, diversos autores apontaram para uma percepção crescente sobre a necessidade de contratação antecipada de projetos com relação as atuais práticas de mercado, a demanda por maior detalhamento dos projetos e a introdução de disciplinas ou especialidades pouco contratadas anteriormente, como é o caso dos aspectos de desempenho térmico e lumínico. São aspectos que impactam nos processos de coordenação de projetos (SANTOS e SANTOS, 2018; MORAIS, 2019. Souza (2016) também pontua que o atendimento aos requisitos de desempenho, e especificamente quando se pretende obter níveis de desempenho distintos dos mínimos previstos na NBR 15.575:2013, implica em significativas mudanças no processo de projeto, o que logicamente impacta nos mecanismos de gestão do processo de projeto.

Por outro lado, faz parte também dos desafios do processo de coordenação da etapa de projeto a determinação de formas de avaliar e assegurar o atendimento dos requisitos de desempenho, dentro dos conceitos de performance based buildings (ALMEIDA et al., 2015; GREENWOOD, 2007).

Além disso, a introdução de processos que permitam aumentar a colaboração entre agentes e fases do empreendimento cresce em importância (WATKINS e FRIEDMAN, 2016).

Nesse contexto, o presente trabalho apresenta os resultados parciais de projeto de pesquisa dos autores, contribuindo para uma melhor compreensão das alterações no processo de projeto de empreendimentos habitacionais tendo em vista o atendimento à NBR 15.575:2013.

Especial atenção é dada a mudanças e inovações na função coordenação de projetos e a interface entre as atividades de projeto e as demais funções da produção de empreendimentos habitacionais. Ou seja, o problema de 
pesquisa é o de determinar em que medidas a implementação de ações para garantia do desempenho, nesse caso referenciado em uma norma, impacta na gestão do processo de projeto, com ênfase nos mecanismos de coordenação.

\section{MÉTODO}

O projeto de pesquisa, em seu contexto mais amplo, teve como foco o desenvolvimento, implementação e avaliação de processos estruturantes das etapas de concepção, projeto e execução de obras tendo em vista a garantia do desempenho, a partir do entendimento das mudanças necessárias nos processos de coordenação de projetos, quer seja tendo em vista a interface entre a etapa de desenvolvimento de projetos e as demais fases dos empreendimentos, quer seja nas interfaces e dependências entre as disciplinas.

Na primeira etapa da pesquisa foi conduzida revisão da literatura, com ênfase no impacto da NBR 15.565:2013 no processo de projeto das empresas incorporadoras e construtoras

Na sequência foi conduzido estudo de caso em várias empresas, que é objeto do presente trabalho. OU seja, esse artigo concentra sua observação na etapa inicial da pesquisa, envolvendo estudos de caso oriundos de diagnósticos realizados sobre o processo de projeto.

Critérios utilizados na seleção das empresas foram:

a) empresas deveriam ser incorporadoras e construtoras com processos de projeto estruturados e com atividades documentadas, de forma a poder se garantir que a análise do processo de projeto de um empreendimento fosse representativa da realidade da empesa;

b) empreendimentos nos quais se pudesse analisar a interface entre projeto e obras, pela atuação conjunta das equipes de projeto e obra, e com a existência de fontes de evidência que pudessem caracterizar essa interface, e

C) disponibilidade para fornecer informações e estarem implementando em seus processos a NBR15.575:2013.

Caracterização das empresas é apresentada no Quadro 1.

Quadro 1 - Caracterização das empresas

\begin{tabular}{|c|c|c|c|}
\hline Empresa & Porte & Atuação & Região \\
\hline A & Grande & $\begin{array}{c}\text { Incorporações comerciais e residenciais de luxo e } \\
\text { no programa Minha Casa Minha Vida (MCMV) }\end{array}$ & MG e RJ \\
\hline B & Grande & $\begin{array}{c}\text { Incorporações no MCMV, empreendimentos acima } \\
\text { de } 300 \text { unidades }\end{array}$ & MG \\
\hline C & Médio & $\begin{array}{c}\text { Incorporações no MCMV, empreendimentos } \\
\text { abaixo de } 300 \text { unidades }\end{array}$ & MG \\
\hline D & Médio & $\begin{array}{l}\text { Incorporações comerciais e residenciais de alto } \\
\text { padrão }\end{array}$ & Belo Horizonte \\
\hline $\mathbf{E}$ & Pequeno & Incorporações no MCMV abaixo de 200 unidades & Belo Horizonte \\
\hline $\mathbf{F}$ & Pequeno & Incorporações MCMV de pequeno porte & DF e GO \\
\hline G & Médio & Edificações residenciais alto padrão & Belo Horizonte \\
\hline
\end{tabular}


Fonte: autores, 2019

Os estudos de caso foram conduzidos entre julho de 2017 e janeiro de 2019, e em todas as empresas envolveram entrevistas com diretores proprietários e diretores de obras (no caso das empresas D, E, e G), coordenadores de projeto e engenheiros de obras. Tiveram o objetivo de fazer um diagnóstico sobre o processo de projeto das empresas, os mecanismos de coordenação e as interfaces entre os processos de coordenação e as demais etapas do desenvolvimento dos empreendimentos.

As entrevistas, com questionários semiestruturados, buscaram caracterizar o nicho de mercado dos empreendimentos, as soluções construtivas (para os sistemas estruturais, fachadas, vedações, etc.), bem como caracterizar processos internos da empresa, em especial os processos associados á contratação, definição de escopo e desenvolvimento de projetos.

Foram realizadas visitas a obras, com registro fotográfico e análise in loco de soluções construtivas, visando o atendimento à NBR 15.5765:2013.

Em cada empresa foram objeto de análise projetos de arquitetura e engenharia, e em alguns casos foi feita a verificação dos projetos, com base em check lists desenvolvidos pelos autores. Também foram analisados documentos do sistema de gestão da qualidade, e em especial a análise dos procedimentos de planejamento de projetos, análise crítica, verificação e validação, bem como processos de análise de riscos que envolvessem as questões de garantia do desempenho.

\section{DISCUSSÃO}

O estudo diagnóstico, corroborou o fato, apontado na literatura recente, de que as empresas estão implementando ações isoladas para atendimento da NBR 15.575:2013, faltando ainda uma visão sistêmica entre agentes, processos e ferramentas.

Excetuando a empresa $C$, que já vem considerando aspectos de desempenho nos estudos preliminares de concepção dos empreendimentos, nas demais empresas essas questões foram em geral consideradas depois de aprovado o projeto legal ou, no melhor dos casos, estando concluído o ante projeto, ainda passível de alterações previamente a sua aprovação legal.

Por outro lado, as empresas vêm acelerando a implementação de check lists de verificação de projetos quanto ao desempenho, assim como a introdução de planos de controle tecnológico que incluem providências por parte da equipe de projetos. Em alguns casos é feita a contratação de especialistas para realização da análise crítica dos projetos quanto ao atendimento aos requisitos de desempenho, o que mostra uma mudança nos processos de coordenação.

Ou seja, o atendimento aos requisitos de desempenho tem sido, conforme constatado na prática das empresas, um acelerador de mudanças e inovações, induzindo uma maior integração entre funções, quer seja entre coordenação de projetos e responsáveis pela incorporação, que seja entre a equipe de projetos e a de obras, na medidas em que soluções construtivas, ainda que definidas muitas vezes tardiamente, passam a ser discutidas e implementadas em conjunto. 
Como indicado acima, a análise das atividades de coordenação de projetos aponta para o fato de que vem diminuindo, em algumas das empresas, a separação entre as áreas de promoção dos negócios imobiliários (seleção do terreno, estudo de viabilidade, concepção do produto e desenvolvimento dos projetos legais) e as fases de desenvolvimento de projetos, já observados como uma mudança trazida pelo atendimento ao desempenho.

Observou-se em alguns casos preocupação com considerar, na análise de viabilidade dos terrenos e empreendimentos, os riscos e dificuldades associadas ao atendimento aos requisitos de desempenho. Nos casos onde isso se deu, houve uma atuação compartilhada entre a função incorporação e a coordenação de projetos, que passou a colaborar com a etapa de definição do produto.

Nessas empresas as funções de coordenação são exercidas por profissionais distintos. Fica nítida a diferenciação de atividades de uma coordenação técnica, especificamente voltada ao desenvolvimento dos projetos e análise de interfaces entre disciplinas, e uma coordenação gerencial, trabalhando as interfaces entre desenvolvimento de produto nas diversas funções da organização e etapas da produção.

Mesmo quando a coordenação de projetos tenha sido exercida por um único profissional, vem se tornando mais nítida a distinção entre as atividades mais técnicas, voltadas às soluções de projeto e interfaces entre disciplinas, e a gerencial, que integra a função desenvolvimento de projetos com as demais funções da produção dos empreendimentos.

Em várias empresas a coordenação de projetos, em conjunto com a equipe responsável pela gestão da qualidade, vem se responsabilizando pela condução de análises de risco e análises de entorno dos terrenos, como passo inicial do processo de projeto, como indicado na seção 6.3, parte 1, da NBR 15.575:2013. Aspectos como condições de incidência sonora, condicionantes associadas aos projetos de fundações e contenções, condições de iluminação, entre outras, são considerados com dados de entrada de projeto.

A coordenação de projetos começa a incorporar em suas rotinas de trabalho, ainda que nem sempre no momento ideal, a contratação de consultorias especializadas para análise de desempenho térmico, lumínico e acústico, com a realização de simulações que balizam soluções de projeto. Nesse sentido, O trabalho também corrobora afirmação anterior (BARBOSA e ANDERY, 2018) ressaltando a contratação de consultorias específicas.

Outro aspecto é a introdução do Plano de Controle Tecnológico, previsto no SiAC 2018, como ferramenta permitindo um planejamento de ações do processo ao longo do fluxo de atividades e ações da coordenação de projetos.

Esses planos indicam os ensaios e controles tecnológicos de materiais e sistemas construtivos nas fases de pré-projeto, projeto e obra.

Foi observado que: a) resultados de ensaios e simulações de desempenho de sistemas construtivos passam a ser referência e entrada de projeto para empreendimentos similares; b) esses mesmos elementos vêm servindo como validadores de soluções construtivas previstas nos projetos; c) as Fichas de Avaliação de Desempenho (FADs), passam a ser empregadas pelos coordenadores de projeto com o mesmo propósito. 
Observou-se também inovações e melhorias no escopo de contratação de projetos e a implementação de check lists para recebimento dos mesmos transferindo aos projetistas a reponsabilidade de evidenciar o atendimento da NBR 15.575:2013.

Ressalta-se a tendência de padronização de produtos (soluções de arquitetura, ou parte delas e padronização de sistemas construtivos), como forma de reduzir os riscos e/ou custos das validações das soluções de projeto.

\section{CONSIDERAÇÕES FINAIS}

O trabalho apontou aspectos da função coordenação de projetos que vêm sofrendo mudanças na realidade das empresas como consequência da implementação da NBR 15.575:2013.

Destacou-se uma maior importância da função coordenação de projetos, exercendo função de integração entre a promoção dos empreendimentos, o planejamento do fluxo, etapas e processos do desenvolvimento dos projetos e a implementação de medidas de garantia de construtibilidade nas obras em busca do adequado comportamento da edificação em seu uso.

\section{REFERÊNCIAS}

ALMEIDA, N., SOUZA, V., DIAS, L. A. e BRANCO, F. A framework for combining risk-management and performance-based buildings approaches. Journal of Building Research \& Information, v. 38, n. 2, p. 157-174, Feb. 2010.

ANDERY, P., BARBOSA, P. Estudo sobre o Impacto do SIAC - Sistema de Avaliação da Conformidade - na Implementação da NBR 15.575:2013 em Empresas Construtoras. In: ENCONTRO NACIONAL DE TECNOLOGIA DO AMBIENTE CONSTRUÍDO, 17., 2018, Foz do Iguaçu. Anais... Porto Alegre: ANTAC, 2018.

ASSOCIAÇÃO BRASILEIRA DE NORMAS TÉCNICAS. ABNT NBR 15575: Edificações habitacionais - Desempenho. Rio de Janeiro, 2013. 283p.

BARBOSA, P. e ANDERY, P. Gestão de projetos para garantia do desempenho: contexto e desafios. Associação Brasileira de Cimento Portland, Belo Horizonte: 2016.

COTA, A., ANDERY, P. As alterações no processo de projeto das empresas construtoras e incorporadoras devido à NBR 15575 - Norma de Desempenho.

Ambiente Construído, Porto Alegre, v. 1 8, n. 1, p. 133-152, 2018.

GEEENWOOD, J. An examination of the performance based building code on the Design of a Commercial Building. Construction Economics and Building, $\vee .7$, n. 1, p. 37-44, Nov. 2007.

MORAIS, G. Desempenho das edificações habitacionais: implementação e diretrizes. 2019. 224 p. Dissertação. (Mestrado em Engenharia Civil). Escola Politécnica da UPE, Recife.

OKAMOTO, P. Os impactos da norma brasileira de desempenho sobre o processo de projeto de edificações residenciais. 2015. 160 p. Dissertação (Mestrado em Engenharia Civil) - Escola Politécnica da Universidade de São Paulo. 
OTERO, J. ; SPOSTO, R. Caracterização da atuação de construtoras e incorporadoras de Goiânia-GO frente às normas de desempenho ABNT NBR 15575:2013. In: ENCONTRO NACIONAL DE TECNOLOGIA DO AMBIENTE CONSTRUÍDO, XVI, 2016, São Paulo. Anais... São Paulo, 2016, 15p.

SANTOS, P. R. R.; SANTOS, D.G. Investigação das mudanças realizadas por construtoras para adaptação à norma de desempenho na concepção de empreendimentos. In: ENCONTRO NACIONALDE TECNOLOGIA DO AMBIENTE CONSTRUÍDO, 17., 2018, Foz do Iguaçu. Anais... Porto Alegre: ANTAC, 2018.

SOUZA, J. Desafios na implantação do nível superior da norma de desempenho em edificação residencial em Novo Hamburgo / RS. 2016. 111 p. Dissertação (Mestrado em Engenharia Civil). Unisinos, Novo Hamburgo.

WATKINS, S. e FRIEDMAN, K. Performance Based Building by U.S. Architects - an investigation into atitudes and adoption. In: PROCEEDINGS OF THE 20th CIB BUILDING CONGRESS, 2016, Tempere, Finland. Proceedings.... Tempere: CIB, 2016. 